\title{
Nuclear IGF1R interacts with NuMA and regulates 53BP1-dependent DNA double-strand break repair in colorectal cancer
}

\author{
CHEN YANG $^{1-3}$, YIFAN ZHANG $^{4}$, NELLY SEGAR $^{3}$, CHANGHAO HUANG $^{1,2}$, PENGWEI ZENG $^{1,2}$, \\ XIANGZHOU TAN ${ }^{1,2}$, LINFENG MAO ${ }^{1,2}$, ZHIKANG CHEN ${ }^{1,2}$, FELIX HAGLUND ${ }^{3,4}$, \\ OLLE LARSSON $^{3}$, ZIHUA CHEN ${ }^{1,2^{*}}$ and YINGBO LIN $^{3 *}$ \\ ${ }^{1}$ Department of General Surgery, Xiangya Hospital of Central South University; ${ }^{2}$ Hunan Key Laboratory of \\ Precise Diagnosis and Treatment of Gastrointestinal Tumor, Changsha, Hunan 410000, P.R. China; \\ ${ }^{3}$ Department of Oncology and Pathology, Karolinska Institute, 17177 Stockholm; \\ ${ }^{4}$ Department of Clinical Pathology and Cytology, Karolinska University Hospital Solna, 17164 Solna, Stockholm, Sweden
}

Received January 31, 2021; Accepted May 12, 2021

DOI: $10.3892 /$ or.2021.8119

\begin{abstract}
Nuclear insulin-like growth factor 1 receptor (nIGF1R) has been associated with poor overall survival and chemotherapy resistance in various types of cancer; however, the underlying mechanism remains unclear. In the present study, immunoprecipitation-coupled mass spectrometry was performed in an IGF1R-overexpressing SW480-OE colorectal cancer cell line to identify the nIGF1R interactome. Network analysis revealed 197 proteins of interest which were involved in several biological pathways, including RNA processing, DNA double-strand break (DSB) repair and SUMOylation pathways. Nuclear mitotic apparatus protein (NuMA) was identified as one of nIGF1R's colocalizing partners. Proximity ligation assay (PLA) revealed different levels of p53-binding protein 1 (53BP1)-NuMA colocalization
\end{abstract}

Correspondence to: Dr Zihua Chen, Department of General Surgery, Xiangya Hospital of Central South University, 87 Xiangya Road, Kaifu, Changsha, Hunan 410000, P.R. China

E-mail: zihuac@126.com

Dr Yingbo Lin, Department of Oncology and Pathology, Karolinska Institute, Solnavägen 1, 17177 Stockholm, Sweden

E-mail: yingbo.lin@ki.se

Abbreviations: nIGF1R, nuclear insulin-like growth factor 1 receptor; NuMA, nuclear mitotic apparatus protein 1; 53BP1, p53-binding protein 1; DSB, DNA double-strand break; SUMO, small ubiquitin-related modifier; PLA, proximity ligation assay; NHEJ, non-homologous end-joining; HR, homologous recombination; TEAB, triethylammonium bicarbonate buffer; IP-MS, immunoprecipitation coupled-mass spectrometry; LC/MS, liquid chromatography mass spectrometry; CAA, chloroacetamide; CAN, acetonitrile; TCEP, $0.5 \mathrm{M}$ bond-breaker TCEP solution; Lys-C, lysyl endopeptidase; TFA, trifluoroacetic acid

Key words: nIGF1R, NuMA, 53BP1, colorectal cancer, DSB repair between IGF1R-positive $\left(\mathrm{R}^{+}\right)$and IGF1R-negative $\left(\mathrm{R}^{-}\right)$ mouse embryonic fibroblasts following exposure to ionizing radiation (IR). 53BP1 was retained by NuMA in the $\mathrm{R}^{-}$cells during IR-induced DNA damage. By contrast, the level of NuMA-53BP1 was markedly lower in $\mathrm{R}^{+}$cells compared with $\mathrm{R}^{-}$cells. The present data suggested a regulatory role of nIGF1R in 53BP1-dependent DSB repair through its interaction with NuMA. Bright-field PLA analysis on a paraffin-embedded tissue microarray from patients with colorectal cancer revealed a significant association between increased nuclear colocalizing signals of NuMA-53BP1 and a shorter overall survival. These results indicate that nIGF1R plays a role in facilitating 53BP1-dependent DDR by regulating the NuMA-53BP1 interaction, which in turn might affect the clinical outcome of patients with colorectal cancer.

\section{Introduction}

Colorectal cancer ranks as the fourth leading cause of mortality worldwide, with $\sim 900,000$ deaths recorded annually (1). It is the second most common type of cancer in women and third most common in men $(1,2)$. Currently, combinatorial treatment based on surgery and adjuvant chemotherapy or radiotherapy remains the main treatment approach for colorectal cancer $(3,4)$. Despite recent developments in targeted therapy and immunotherapy, which have almost doubled the overall survival time for non-metastatic cases to three years, clinicians are still facing significant challenges when dealing with advanced or treatment-resistant tumors $(2,3)$. Understanding the mechanism of tumor progression, metastasis and treatment resistance in colorectal cancer is crucial to improving prognosis.

The insulin-like growth factor 1 receptor (IGF1R) is a membrane-based receptor tyrosine kinase (RTK) that plays various roles in multiple biological events, including cell growth, transformation, apoptosis, migration and invasion in both physiological and pathological conditions (5-8). Similar to other RTKs, the conventional activation for IGF1R requires 
ligand-receptor binding with IGF1, which in turn activates the PI3K-Akt and MAPK pathways $(9,10)$. Our previous studies reported that upon SUMOylation, membranous IGF1R could undergo nuclear translocation and serve as a transcription co-factor, thus regulating various cellular functions (11-14). Other previous studies have revealed an association between nuclear IGF1R (nIGF1R) and cell proliferation, tumorigenicity, resistance to EGFR inhibition and DNA repair $(6,15-17)$; however, a global network study for protein function is still required.

DNA double-strand breaks (DSBs) arise regularly in cells and, when left unrepaired, cause senescence or cell death. Homologous recombination (HR) and non-homologous end-joining (NHEJ) are the two major DNA-repair pathways (18). While HR allows successful DSB repair and healthy cell growth, NHEJ is more likely to contribute to mutations and malignancy (18-20). When DSBs are detected, the histone variant $\mathrm{H} 2 \mathrm{AX}$ is phosphorylated by ataxia-telangiectasia mutated kinase, which leads to the recruitment of mediator of DNA damage checkpoint protein 1 (MDC1) and activation of ring finger protein (RNF)8/RNF168-dependent chromatin ubiquitination. p53-binding protein 1 (53BP1) then binds to the ubiquitinated histone and recruits RAP1-interacting factor 1 (RIF1), thus preventing the activation of the HR pathway induced by the association between breast cancer 1 and MRE11 homolog, double strand break repair nuclease-RAD50 double strand break repair protein-nibrin complex-bound CtBP-interacting protein $(21,22)$. NHEJ is initiated by the rapid binding of the $\mathrm{X}$-ray repair cross complementing 6-X-ray repair cross complementing 5 (Ku80) heterodimer to the DNA ends, followed by the recruitment and activation of DNA-dependent protein kinase catalytic subunit (DNA-PKcs) (20). During DSB repair, 53BP1 serves not only as an important DSB-responsive factor, but a key determinant of DSB repair pathway choice. It has been reported that 53BP1 colocalizes and interacts with the structural protein nuclear mitotic apparatus protein (NuMA) through the nucleoplasm. In response to ionizing radiation (IR), the interaction is reduced to allow 53BP1 to accumulate at DSB sites (23). Studies by Chitnis et al have indicated that nIGF1R plays a pivotal role in regulating DSB repair by both NHEJ and HR pathways $(15,24)$; however, the regulatory mechanism of this process remains unclear.

In the present study, we investigated the interactome of nIGF1R in colorectal cancer cell line SW480 using immunoprecipitation-mass spectrometry (IP-MS) method. Validation of protein-protein interaction between NuMA and nIGF1R was conducted using co-immunoprecipitation and in situ proximity ligation assay (PLA). The role of nIGF1R in modulating the NuMA-53BP1 complex and NHEJ repair pathway was further illustrated by in situ PLA and immunofluorescence. The clinical significance of NuMA-53BP1 and IGF1R-NuMA colocalization in colorectal cancer was investigated using PLA in FFPE tissue samples.

\section{Materials and methods}

Cell culture and transfection. IGF1R-negative [( $\left.\mathrm{R}^{-}\right)$; mouse embryonic fibroblast (MEF) $\left.i g f l r^{-/}\right]$and IGF1R-positive ( $\mathrm{R}^{+}$; R-overexpressing IGF1R) cells were obtained from
Dr R. Baserga (Thomas Jefferson University; Philadelphia, PA, USA). The SW480 colorectal cancer cell line was purchased from the American Type Culture Collection. All cell lines were cultured in high-glucose DMEM (cat. no. 41965039; Thermo Fisher Scientific, Inc.) supplemented with $10 \%$ FBS (cat. no. 16000044; Thermo Fisher Scientific, Inc.). All cell lines were maintained at $37^{\circ} \mathrm{C}$ in a humidified atmosphere containing $5 \% \mathrm{CO}_{2}$ and controlled for mycoplasma contamination using a Mycoalert ${ }^{\mathrm{TM}}$ kit (cat. no. LT07-418; Lonza Group Ltd.). All human cell lines were short tandem repeat-authenticated using an AmpFLSTR ${ }^{\circledR}$ Identifiler $^{\circledR}$ Plus kit (cat. no. A26182; Thermo Fisher Scientific, Inc.).

The IGF1R cDNA sequence was subcloned into a pBABE-puro vector (Cell Biolabs, Inc.) and transfected into a Platinum-A cell line (Cell Biolabs, Inc.) for lentivirus packaging, according to the manufacturer's instructions. To establish a stable IGF1R-overexpressing cell line, SW480 cells were seeded into 24 -well plates and infected with IGF1R-coding lentivirus particles 24 and $48 \mathrm{~h}$ following seeding. A total of $96 \mathrm{~h}$ after infection, cells were sorted into single cells in 96-well plates and selected with $2.5 \mu \mathrm{g} / \mathrm{ml}$ puromycin. After 2 weeks, the cell colonies were selected and IGF1R overexpression was verified by western blot analysis. The newly established IGF1R-overexpressing colorectal cancer cell line was defined as SW480-OE.

Nuclear protein extraction and IP. Nuclear protein extraction was conducted in cells, as previously described (25), and is schematically shown in Fig. 1A.Cells were removed and successively lysed in hypotonic lysis buffer (10 mM HEPES, pH 7.4, $10 \mathrm{mM} \mathrm{KCl}$ and $0.05 \%$ Nonidet P-40). Then, RIPA lysis buffer (50 mM Tris, pH 7.4, $150 \mathrm{mM} \mathrm{NaCl,} \mathrm{1 \%} \mathrm{Nonidet} \mathrm{P-40,} 1 \mathrm{mM}$ EDTA and $0.25 \%$ sodium deoxycholate) containing Protease and Phosphatase Inhibitor Cocktail (cat. no. 78447; Thermo Fisher Scientific, Inc.) was used to extract the nuclear extract. Protein concentration was measured using a Pierce ${ }^{\mathrm{TM}}$ BCA Protein Assay kit (cat. no. 23227; Thermo Fisher Scientific, Inc.). Nuclear protein (2-4 mg) was incubated with 4-7 $\mu \mathrm{g}$ mouse anti-IGF1R (cat. no. 556000; BD Biosciences) antibody coupled with Dynabeads ${ }^{\mathrm{TM}}$ Protein A (cat. no. 10002D; Thermo Fisher Scientific, Inc.) overnight at $4^{\circ} \mathrm{C}$. The immune complexes were washed three times with lysis buffer and eluted by boiling in SDS sample buffer (cat. no. NP0007; Thermo Fisher Scientific, Inc.).

In-gel digestion and sample preparation. The eluted proteins were separated by SDS-PAGE on a NuPAGE 4-12\% Bis-Tris protein Gel (Thermo Fisher Scientific, Inc.). The proteins were visualized using the Colloidal Blue Staining kit (Thermo Fisher Scientific, Inc.). Gels were cut into eight bands according to the molecular mass. Each gel band was cut into $1-\mathrm{mm}^{2}$ pieces and placed in a microcentrifuge tube. The gels were destained [1:1 (v/v) mixture of $50 \mathrm{mM}$ triethylammonium bicarbonate buffer (TEAB) and $100 \%$ acetonitrile (ACN)] for $10 \mathrm{~min}$, which was repeated until the solution was clear. Subsequently, the gels were incubated with $5 \mathrm{mM}$ TCEP $[0.5 \mathrm{M}$ bond-breaker TCEP solution (Thermo Fisher Scientific, Inc.)] (in $50 \mathrm{mM} \mathrm{TEAB}$ ) for $30 \mathrm{~min}$ at $65^{\circ} \mathrm{C}$, followed by a $30-\mathrm{min}$ incubation at $37^{\circ} \mathrm{C}$ with $15 \mathrm{mM}$ chloroacetamide (in $50 \mathrm{mM}$ TEAB). Lys-C [lysyl endopeptidase (Wako Chemicals Ltd.)] 
A

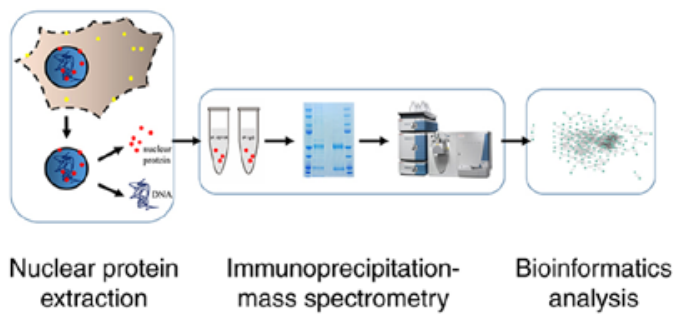

B

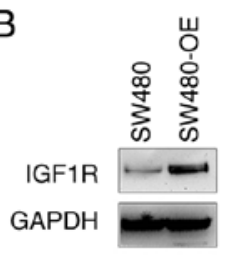

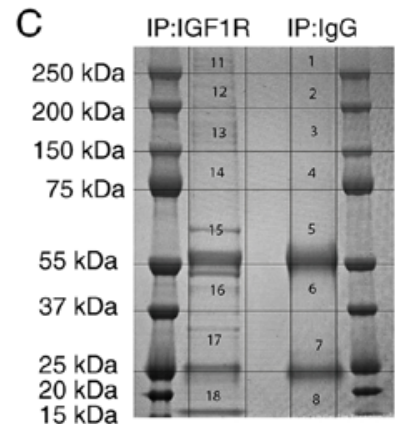

Top 10 protein enrichment ratio by IP-MS

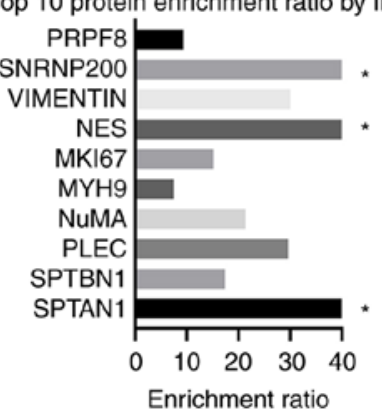

DSB protein enrichment ratio by IP-MS

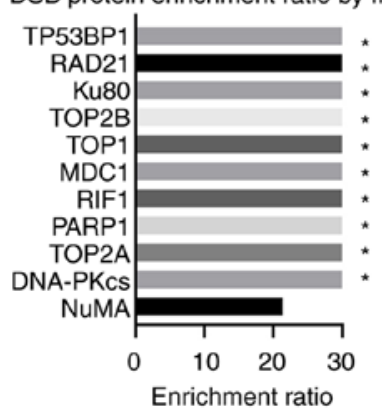

Figure 1. nIGF1R is associated with nuclear proteins, including NuMA, as identified by IP-MS. (A) Diagram showing the experimental workflow. Nuclear proteins were extracted and immunoprecipitated with an anti-IGF1R antibody. Pull-down proteins were separated with SDS-PAGE, in-gel digested and subjected to MS analysis. The readouts were then bioinformatically processed for nIGF1R interactome generation. (B) The SW480 colorectal cancer cell line was infected with IGF1R-coding lentivirus and selected with antibiotic (puromycin). One cell clone that overexpressed IGF1R was named SW480-OE and used for subsequent IP-MS. Western blot analysis detected a significantly higher IGF1R expression in SW480-OE cells compared with untransfected SW480 cells. GAPDH was used as the loading control. (C) Immunoprecipitated nuclear proteins were separated by SDS-PAGE and visualized using a Colloidal Blue Staining kit (left lane). The whole gel lane was cut into eight pieces according to molecular mass and subjected to MS. Normal mouse IgG was used to replace the anti-IGF1R antibody as the negative control (right lane). The corresponding eight areas in the gel lane were cut, MS-processed and used as background control in bioinformatics analyses. (D) IP-MS-identified nIGF1R interactome ranked by Score (defined as sum ion score of identified protein peptide by IP-MS) and enrichment ratio. The upper bar chart shows the top 10 proteins interacting with nIGF1R. The bottom bar chart shows the top 10 DSB-related proteins interacting with nIGF1R. "Protein discovered in the IP group but not the IgG group. nIGF1R, nuclear insulin-like growth factor 1 receptor; NuMA, nuclear mitotic apparatus protein; IP-MS, immunoprecipitation-coupled mass spectrometry.

and trypsin were prepared in $50 \mathrm{mM}$ acetic acid and added to the sample (50:1 protein:enzyme ratio). The incubation time of Lys-C and trypsin was $4 \mathrm{~h}$ and overnight at $37^{\circ} \mathrm{C}$, respectively. The supernatants were transferred to a clean tube and gel pieces were washed with $60 \% \mathrm{ACN}$ and $5 \%$ trifluoroacetic acid (TFA) in Milli-Q water. This step was repeated, and supernatants were collected and dried in a vacuum centrifuge for $2-3 \mathrm{~h}$. The samples were resuspended in $0.1 \%(\mathrm{v} / \mathrm{v})$ formic acid in Milli-Q for liquid chromatography-mass spectrometry (LC-MS).

LC-MS/MS and database search. Online chromatography was performed using Dionex UltiMate 3000 UPLC system coupled to a Q Exactive HF mass spectrometer (Thermo Fisher
Scientific, Inc.). Each sample was separated on a $50 \mathrm{~cm} \times 75 \mu \mathrm{m}$ EASY-Spray analytical column (Thermo Fisher Scientific, Inc.) using a 120-min gradient of a programmed mixture of solvents A ( $0.1 \%$ formic acid in water) and B $(95 \% \mathrm{ACN}$ and $5 \%$ water with $0.1 \%$ formic acid). MS data were acquired using a Top 12 data-dependent acquisition method. Full Scan MS spectra were acquired at $300-1,600 \mathrm{~m} / \mathrm{z}$ at a resolution of 70,000 and AGC target of 3e6; Top12 ddMS2 35,000 and 1e5 with an isolation window of $1.6 \mathrm{~m} / \mathrm{z}$.

Proteome Discoverer 2.1 software (Thermo Fisher Scientific, Inc.) was used to analyze the Xcalibur ${ }^{\circledR}$ raw files for subsequent protein identification and quantification. Both Mascot 2.6.0 (Matrix Science, Inc.) and Sequest HT (Thermo Fisher Scientific, Inc.) search engines were used to search 
against the human-reviewed UniProt database. MS precursor mass tolerance was set at $20 \mathrm{ppm}$, fragment mass tolerance at $0.05 \mathrm{Da}$ and maximum missed cleavage sites at 3 . Only the spectrum peaks with a signal-to-noise ratio of $>4$ were chosen for searches. The false discovery rate was set to $1 \%$ at both the peptide-spectrum match (PSM) and peptide levels. The Mascot score threshold for PSM was set at 10 .

Bioinformatics analysis of MS data. Gene Ontology (GO) term and Reactome pathway enrichment analyses were performed using the Search Tool for the Retrieval of Interacting Genes/Proteins (STRING) database in Cytoscape software (https://string-db.org/), and the enrichment was calculated using the human genome as a reference $(26,27)$.

Western blot analysis. Eluted proteins were separated by SDS-PAGE on NuPage 4-12\% Bis-Tris Protein Gels (Thermo Fisher Scientific, Inc.) and incubated with the following primary antibodies: Rabbit anti-IGF1R (1:1,000, cat. no. 3024; Cell Signaling Technology, Inc.), rabbit anti-NuMA (1:800, cat. no. 8967; Cell Signaling Technology, Inc.), mouse anti- $\beta$-actin $(1: 5,000$, cat. no. A5441; Merck KGaA) and rabbit anti-53BP1 (1:1,000, cat. no. NB100-904; Novus Biologicals). Following the primary antibody incubation, the membranes were incubated with secondary anti-rabbit (1:2,000, cat. no. NA934; GE Healthcare), -mouse $(1: 2,000$, cat.no. NA931; GE Healthcare) or -goat (1:2,000, cat. no. 31402; Thermo Fisher Scientific, Inc.) IgG HRP-conjugated antibodies, followed by signal detection using an iBright FL1500 imaging system (Thermo Fisher Scientific, Inc.). At least three independent experiments were performed.

Fluorescent in situ proximity ligation assay (PLA) in cell slides. Cells were seeded onto coverslips, fixed with $4 \%$ PBS-buffered paraformaldehyde and permeabilized with $0.1 \%$ Triton X-100. Following blocking for $30 \mathrm{~min}$ in blocking buffer $(5 \%$ BSA, $5 \%$ donkey serum and $0.3 \%$ Triton $\mathrm{X}-100$ in PBS), cells were stained according to the manufacturer's instructions of Duolink ${ }^{\circledR}$ In Situ Detection reagents (Merck $\mathrm{KGaA}$ ). Protein-protein interactions were visualized as foci using a Zeiss LSM710 confocal microscope (Carl Zeiss AG) and analyzed using ImageJ software (V_1.8.0_172, National Institutes of Health). The antibodies used in PLA were diluted in antibody diluent as follows: For IGF1R-NuMA colocalization, mouse anti-IGF1R (cat. no. sc-390130; dilution, 1:50; Santa Cruz Biotechnology, Inc.) and rabbit anti-NuMA (cat. no. 8967; dilution, 1:100; Cell Signaling Technology, Inc.); for NuMA-53BP1 colocalization, rabbit anti-53BP1 (cat. no. NB100-904; dilution, 1:150; Novus Biologicals) and mouse anti-NuMA (cat. no. sc-56325; dilution, 1:50; Santa Cruz Biotechnology, Inc.). At least three independent experiments were performed.

Patient selection and tissue microarray (TMA) preparation. This study was approved by the Medical Ethics Committee of Xiangya Hospital of Central South University (Changsha, China; approval. no. 201403168). All patients provided written informed consent for the use of their surgical specimens for pathological examination. No personal information was disclosed in this article. Between January 2014 and
December 2016, 73 colorectal cancer and paired adjacent non-tumor tissues and related clinical information were collected from patients who underwent radical colorectal surgery at the Department of General Surgery, Xiangya Hospital of Central South University. All tissues collected were clinically and pathologically diagnosed as colorectal cancer.

TMA preparation was conducted as previously described (28). Tissues were excised and fixed in $10 \%$ neutral-buffered formalin and then embedded in paraffin blocks. Each paraffin-embedded section was cut into $4-\mu \mathrm{m}$ thick sections, deparaffinized and rehydrated. Hematoxylin and eosin staining was performed to detect and mark typical tumor sections in colorectal cancer tissues and the normal colorectal mucosa in adjacent tissues, and was evaluated by a professional pathologist. Paraffin-embedded sections measuring 2-mm in diameter were separated from the original section, arranged and re-embedded into the tissue microarray. A total of 73 colorectal cancer and normal colorectal mucosa tissues were collected from different patients in each tissue microarray slide.

PLA scoring for TMA. The slides were rehydrated by incubation in xylene for $10 \mathrm{~min}$, graded ethanol solutions (3x99, 2x95 and $1 \times 70 \%$ ) for 2 min each and washed with running water for $2 \mathrm{~min}$. For antigen retrieval, the sections were incubated in citrate antigen retrieval solution (cat. no. S1699; Dako; Agilent Technologies, Inc.) and microwaved at $750 \mathrm{~W}$ for $8 \mathrm{~min}$ and then at $350 \mathrm{~W}$ for $20 \mathrm{~min}$ (sub-boiling). After cooling the tissue sections in a water bath with running water for $10 \mathrm{~min}$, the intrinsic peroxidase activity was quenched by incubation in an $\mathrm{H}_{2} \mathrm{O}_{2}$ solution (dilution, 1:60; Merck KGaA) and incubated in the dark at room temperature for $30 \mathrm{~min}$. The following steps were performed according to the Duolink ${ }^{\circledR}$ PLA BrightField Protocol (Merck KGaA).

The TMAs were scored blindly by a clinical pathologist. Total and nuclear PLA signals were evaluated for both IGF1R-NuMA and NuMA-53BP1. Tumors were arbitrarily classified for statistical comparisons: Tumors with no or very few signals were scored as 0-1 (negative/weak); tumors with moderate signals (5-10 per cell/nuclei in the majority of cells) were scored as 2 (intermediate); and tumors with abundant signals ( $>10$ signals per cell/nuclei in the majority of cells) were scored as 3 (strong).

The clinical implication of IGF1R and NuMA was further assessed using The Cancer Genome Atlas (TCGA, https://portal.gdc.cancer.gov/).

Statistical analysis. Statistical significance was assessed using an unpaired Student's t-test using GraphPad Prism 8 (GraphPad Software, Inc.). To assess the prognostic significance of PLA staining in the TMAs, a $\chi^{2}$ test was used. Overall survival was compared by Kaplan-Meier estimator and differences were calculated using a log-rank test. $\mathrm{P}<0.05$ was considered statistically significant.

\section{Results}

Characterizing the $n I G F 1 R$ interactome in colorectal cancer cells. To further understand the function of IGF1R in the 
colorectal cancer cell nuclei, immunoprecipitation-coupled mass spectrometry (IP-MS) was conducted on the nuclear protein extract of the IGF1R-overexpressing SW480-OE cell line (Fig. 1A and B). All IGF1R and IgG pulled-down proteins were eluted and separated by SDS-PAGE electrophoresis, and the gel was cut into pieces for enrichment in MS detection (Fig. 1C). A total of 328 IGF1R-pulldown proteins were identified following the initial database search; $\geq 1.5$-fold higher abundance was required for the proteins in the IGF1R pulled-down group compared with the $\operatorname{IgG}$ group to qualify as potential nIGF1R interactors, to distinguish from background binding proteins. In addition, common contaminants in the mass spectrometer were eliminated as previously described (29). Within these criteria, 197 potential nIGF1R interacting proteins were categorized and included in the following network analysis (Tables SI and SII). The top 10 enriched interacting proteins ranked by Score (defined as sum ion score of identified protein peptide by IP-MS) out of all the protein targets and those from the DSB repair pathway are listed in Fig. 1D.

Network analysis of nIGFIR interactome. GO term and Reactome database enrichment analyses were performed using the STRING database in Cytoscape software. Highly enriched functional pathways revealed by Biological Process analysis included 'RNA process', 'Nucleic metabolic process' and 'Nucleobase-containing compound metabolic process', along with several less enriched functional pathways, such as 'Cellular component organization or biogenesis', 'RNA splicing' and 'DNA metabolic process pathways'. The most enriched pathways as identified by Reactome analysis were 'RNA processing', 'Cell cycle', 'SUMOylation' and 'DNA repair' (Fig. 2A and B). This was in line with our previous finding that IGF1R serves as a transcription cofactor (11), and that IGF1R SUMOylation leads to its nuclear translocation $(12,14)$.

The DNA repair pathway was among the most enriched pathways in the network analysis. Key components of DSB repair pathways were detected (Table SII), including the 53BP1-RIF1 complex, Ku80 and DNA-PKcs, which are considered to be the key regulators in the NHEJ pathway (30). Other identified key regulators included poly[ADP-ribose] polymerase 1 (PARP1), and DNA topoisomerases (TOP) I and II (31-33).

IGFIR facilitates the binding between NuMA and 53BPI. Although the role of nIGF1R in the DNA repair pathway has been reported by previous studies to involve the promotion of DSB repair by IGF1R through both NHEJ and HR $(15,24)$, the underlying mechanism remains unclear. Based on the present IP-MS data, NuMA was identified as an nIGF1R co-localizing partner (Fig. 3A) and stood out as one of the most enriched targets in the list (Fig. 1D and Table SI). The interaction between IGF1R and NuMA was further validated by co-IP and in situ PLA (Fig. 3B and C). The dynamics of the IGF1R-NuMA interaction in both $\mathrm{R}^{+}$and SW480 cells was also investigated, but no significant change was reported in any of the cells within $16 \mathrm{~h}$ from IR (Fig. S1).

Despite its various roles in mitotic activities (34-36), NuMA has been associated with multiple other biological processes, including DSB repair. Most recently, Salvador Moreno et al (23) reported that NuMA retained 53BP1 mobility outside the repairing foci to control 53BP1 distribution, which prevented 53BP1 accumulation at the DSBs. We hypothesized that the IGF1R-NuMA interaction might regulate the NuMA-53BP1 complex to regulate DSB repair. In order to validate this

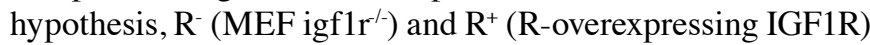
cell lines were used to examine the cellular response to IR in the presence and absence of IGF1R. The baseline NuMA-53BP1 colocalization level was approximately the same between the $\mathrm{R}^{-}$and $\mathrm{R}^{+}$cell lines. In response to IR, colocalizing signals in the $\mathrm{R}^{-}$cells were markedly increased, while PLA signals in the $\mathrm{R}^{+}$cells were barely changed in the cell nuclei (Fig. 3D and E). The NuMA-53BP1 colocalization dynamic was also examined in SW480 and SW480-OE cells following IR. However, no significant difference between SW480 and SW480-OE cells was observed (Fig. S2). This was interpreted as a sign that the existence of endogenous nIGF1R in SW480 had already reached the saturation point.

NuMA-53BP1 colocalization in the nucleus predicts poor survival in patients with colorectal cancer. Next, it was investigated whether the IGF1R-NuMA and NuMA-53BP1 interactions carry clinical significance in tissue samples from patients with colorectal cancer. According to survival analysis based on TCGA (http://gepia.cancer-pku.cn), none of the three analyzed proteins (IGF1R, NuMA and 53BP1) exhibited a significant association with overall or disease-free survival in patients with colorectal cancer (Fig. 4A), despite their well-known oncogenic functions in various molecular biological studies. Therefore, PLA-based survival analysis was conducted to examine whether protein-protein interactions in tumor samples indicated a significant prognostic value. The clinical characteristics of the cohort are presented in Table I. The present study cohort consisted of 73 patients with colorectal cancer (43 males and 30 females aged 33-86 years). Complete clinical follow-up information was available for 56 patients.

In general, the PLA signals in paraffin-embedded TMA slides exhibited a different pattern than that of fixed cells on cover slides. More cytoplasmic IGF1R-NuMA colocalizing signals were observed in the TMAs (Fig. 4B). A higher IGF1R-NuMA and NuMA-53BP1 colocalization was observed in tumor vs. adjacent non-tumor tissues in the whole cell ( $\mathrm{P}=0.0153$ and $\mathrm{P}=0.0316$, respectively) but not in the nucleus $(\mathrm{P}=0.1587$ and $\mathrm{P}=0.8707$, respectively).

Semi-quantitative scoring revealed that $45 / 73(61.6 \%)$ tumors had strong nuclear IGF1R-NuMA signals and 31/73 $(42.5 \%)$ had strong nuclear NuMA-53BP1 signals. Total IGF1R-NuMA colocalization was found to be significantly associated with tumor invasiveness ( $\mathrm{T}$ stage; $\mathrm{P}=0.039$ ), while total NuMA-53BP1 colocalization was shown to be associated with regional nerve metastasis $(\mathrm{P}=0.025$; Table I). Survival analysis showed that strong nuclear 53BP1-NuMA colocalization was associated with poor survival $(\mathrm{P}<0.001$; low-rank test; Fig. 4C).

\section{Discussion}

Despite advances in the study of the various oncogenic roles of nuclear insulin-like growth factor 1 receptor 


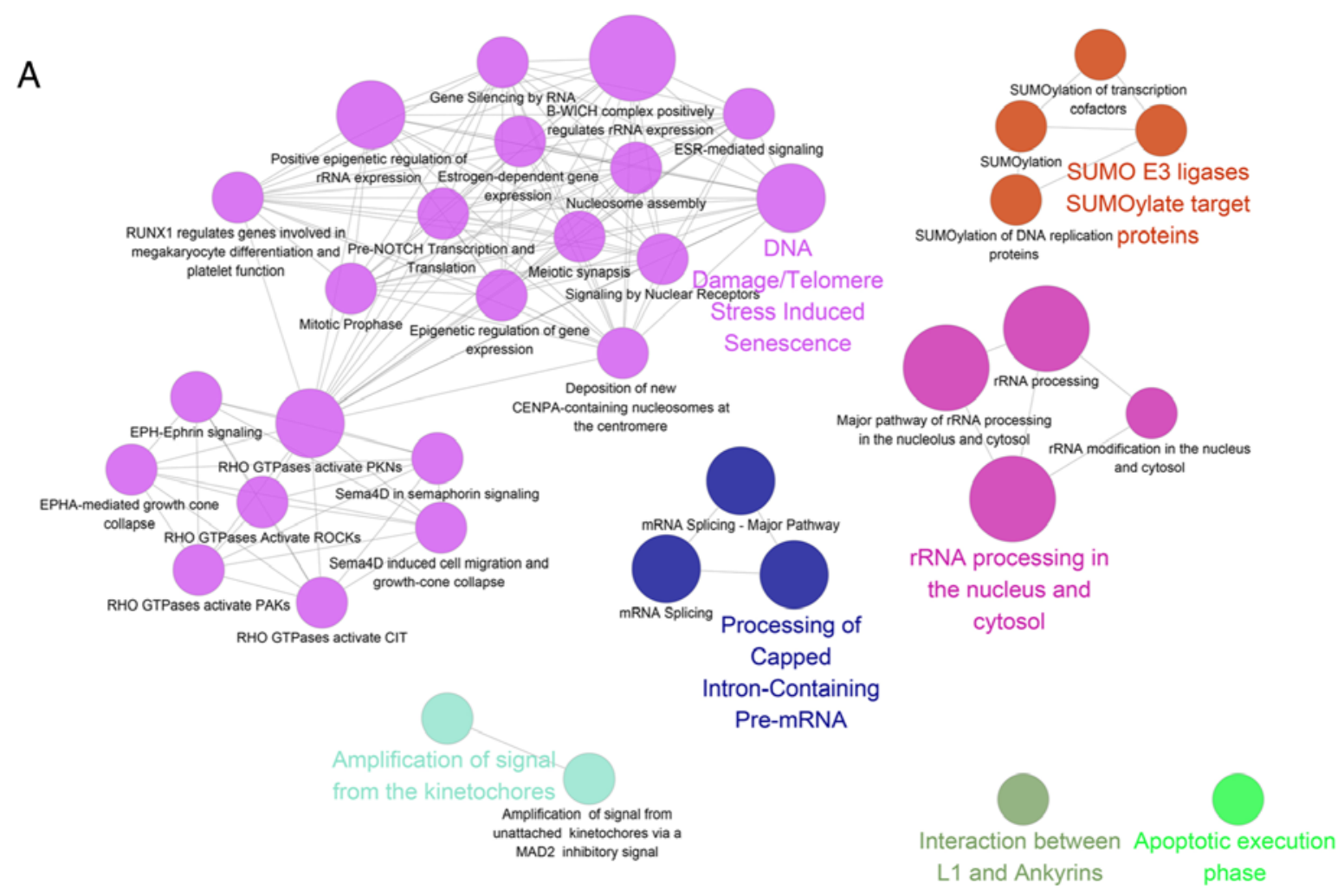

B

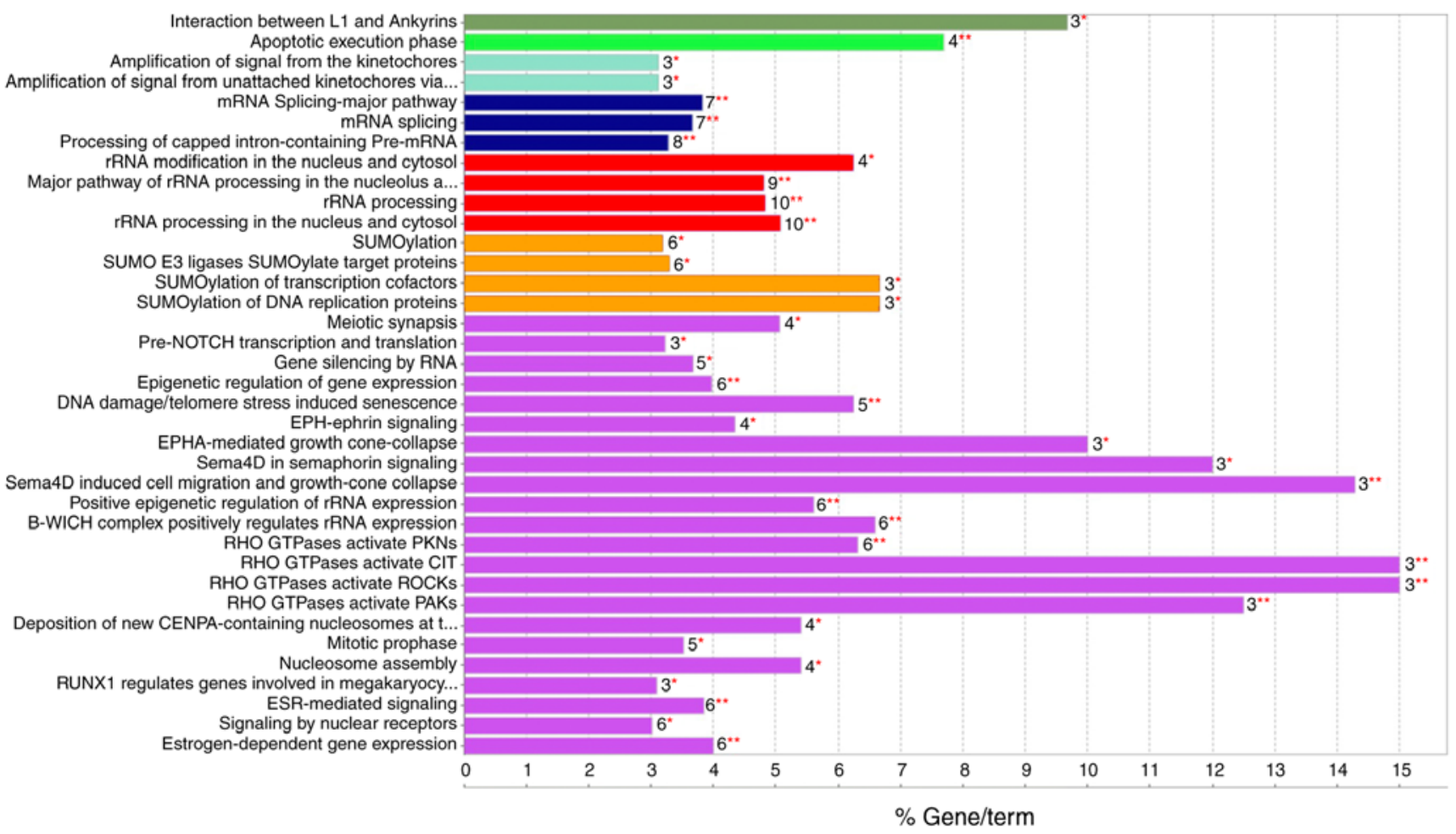

Figure 2. nIGF1R interactors identified in the IP-MS were subjected to Reactome pathway enrichment analysis using STRING database in Cytoscape software and calculated using the human genome as a reference. (A) Reactome pathway enrichment of nIGF1R interactome indicated that the RNA processing (blue and lilac), SUMOylation (orange) and DNA repair (pink) pathways were among the most enriched pathways. (B) Bar chart for Reactome pathway enrichment. ${ }^{*} \mathrm{P} \leq 0.05,{ }^{* *} \mathrm{P} \leq 0.01$. nIGF1R, nuclear insulin-like growth factor 1 receptor; IP-MS, immunoprecipitation-coupled mass spectrometry; STRING, Search Tool for the Retrieval of Interacting Genes/Proteins.

(IGF1R), the targeting of the IGF axis in cancer treatment has yielded disappointing results (37-40). One plausible strategy includes the use of combination therapy, for which an in-depth understanding of nIGF1R function is essential. Although nIGF1R is known for its various functions in cell growth and proliferation, as well as metastasis and DSB 
A
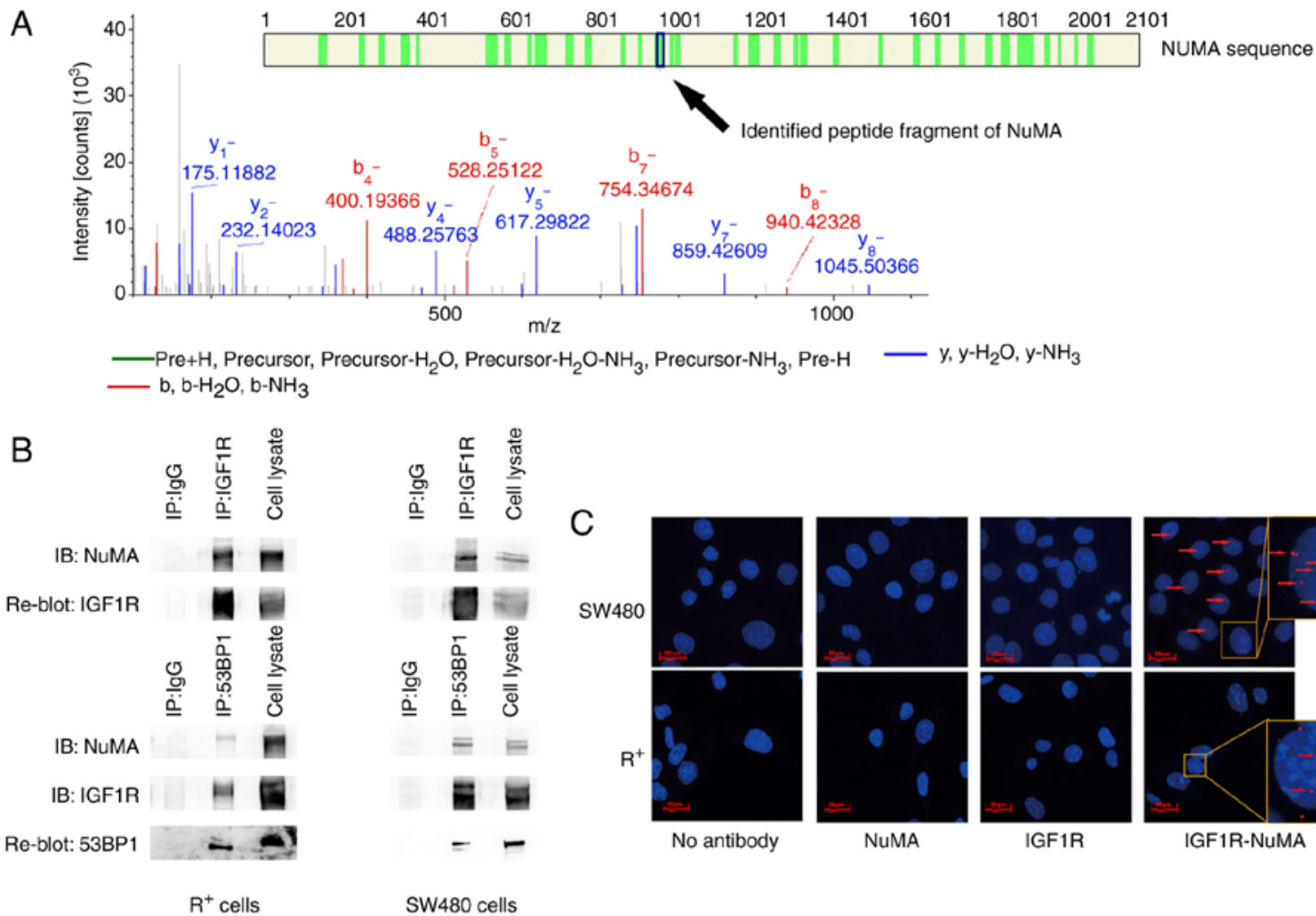

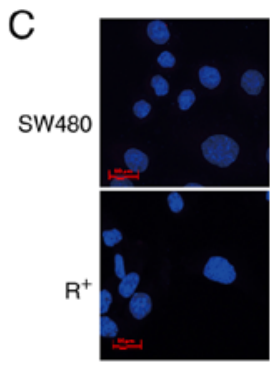

No antibody

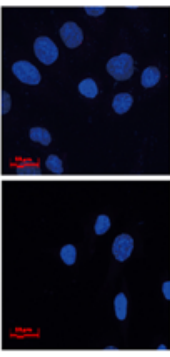

NuMA

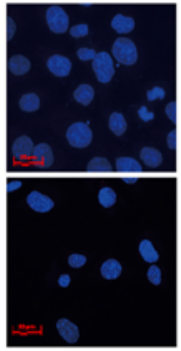

IGF1R

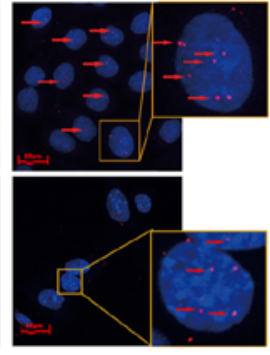

IGF1R-NuMA

SW480 cells

D
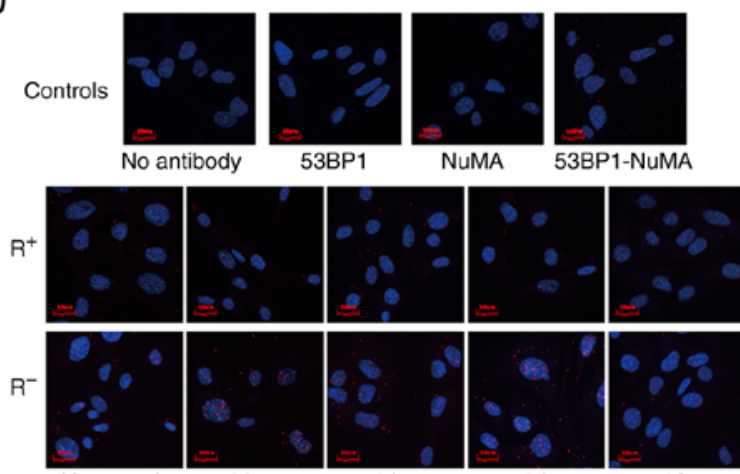

$1 \mathrm{~h}$

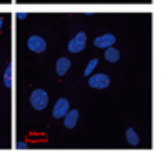

$4 \mathrm{~h}$

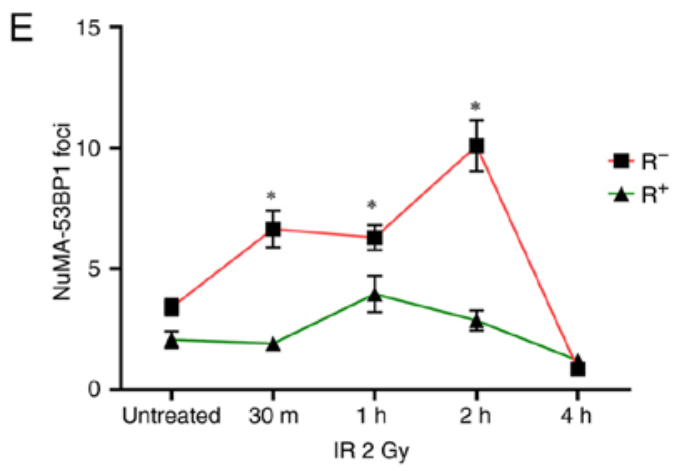

Figure 3. nIGF1R interacts with NuMA and facilitates NuMA-53BP1 colocalization in response to IR. (A) Candidate peptides of NuMA, from which theoretical spectra were sequentially generated and compared against experimental spectra identified by IP-MS. (B) Co-IP with anti-IGF1R antibody validated nIGF1R colocalization with NuMA in SW480 colorectal cancer and $\mathrm{R}^{+}$(R-overexpressing IGF1R) cell lines (upper panel). Co-IP with anti-53BP1 antibody validated 53BP1 colocalization with NuMA and IGF1R in SW480 and $\mathrm{R}^{+}$cell lines (lower panel). IP antibodies were replaced with normal mouse IgG as the negative control. (C) In situ PLA validated nIGF1R colocalization with NuMA using anti-IGF1R and anti-NuMA antibodies in SW480 (upper panel) and R+ (lower panel) cell lines. Red fluorescence dots (arrows) indicate the colocalizations. Either primary antibody or both were removed from the experiment to generate negative controls (first three images). Cell nuclei were stained with DAPI (blue). (D) In situ PLA showed that NuMA-53BP1 colocalization (red dots) was increased in response to IR $(2 \mathrm{~Gy})$ in $\mathrm{R}^{-}\left(\mathrm{MEF}\right.$ igf $1 \mathrm{r}^{--)}$cell line but remained unchanged in the $\mathrm{R}^{+}$cell line. Cell nuclei were stained with DAPI (blue). (E) Dynamic change of NuMA-53BP1 colocalization in response to IR ( $2 \mathrm{~Gy}$ ) in $\mathrm{R}^{+}$and $\mathrm{R}^{-}$cell lines at 30 min, and 1,2 and $4 \mathrm{~h}$ after treatment. Number of NuMA-53BP1 foci represents the average in situ PLA signal per cell from at least 50 cells in each condition. *P<0.05. nIGF1R, nuclear insulin-like growth factor 1 receptor; NuMA, nuclear mitotic apparatus protein; 53BP1, NuMA-p53-binding protein 1; IP-MS, immunoprecipitation-coupled mass spectrometry; IR, ionizing radiation; PLA, proximity ligation assay; ${ }^{+}$, IGF1R-positive; R-, IGF1R-negative; MEF, mouse embryonic fibroblast.

repair $(13,17,25,41-43)$, understanding of the regulatory mechanisms remains limited. In the present study, proteomics and global network analyses were performed to identify the functional partners of nIGF1R in colorectal cancer cells. The identification of 197 potential nIGF1R colocalizing proteins suggested that nIGF1R was functionally associated with various biological pathways.

The global network analysis identified significant enrichment in RNA processing, which is a large and complex pathway that includes RNA transcription, pre-mRNA splicing, and RNA editing, transport, translation and degradation (44). Our and other previous studies have implicated nIGF1R in RNA regulation, including transcription activation $(13,14,16)$. Aleksic et al (41) showed that IGF1R may be recruited to chromatin, directly binding DNA and interacting with RNA polymerase II. In this study, nIGF1R was found to interact with key proteins of the spliceosomes, including pre-mRNA processing factor (PRPF)8, PRPF6, spliceosome associated 

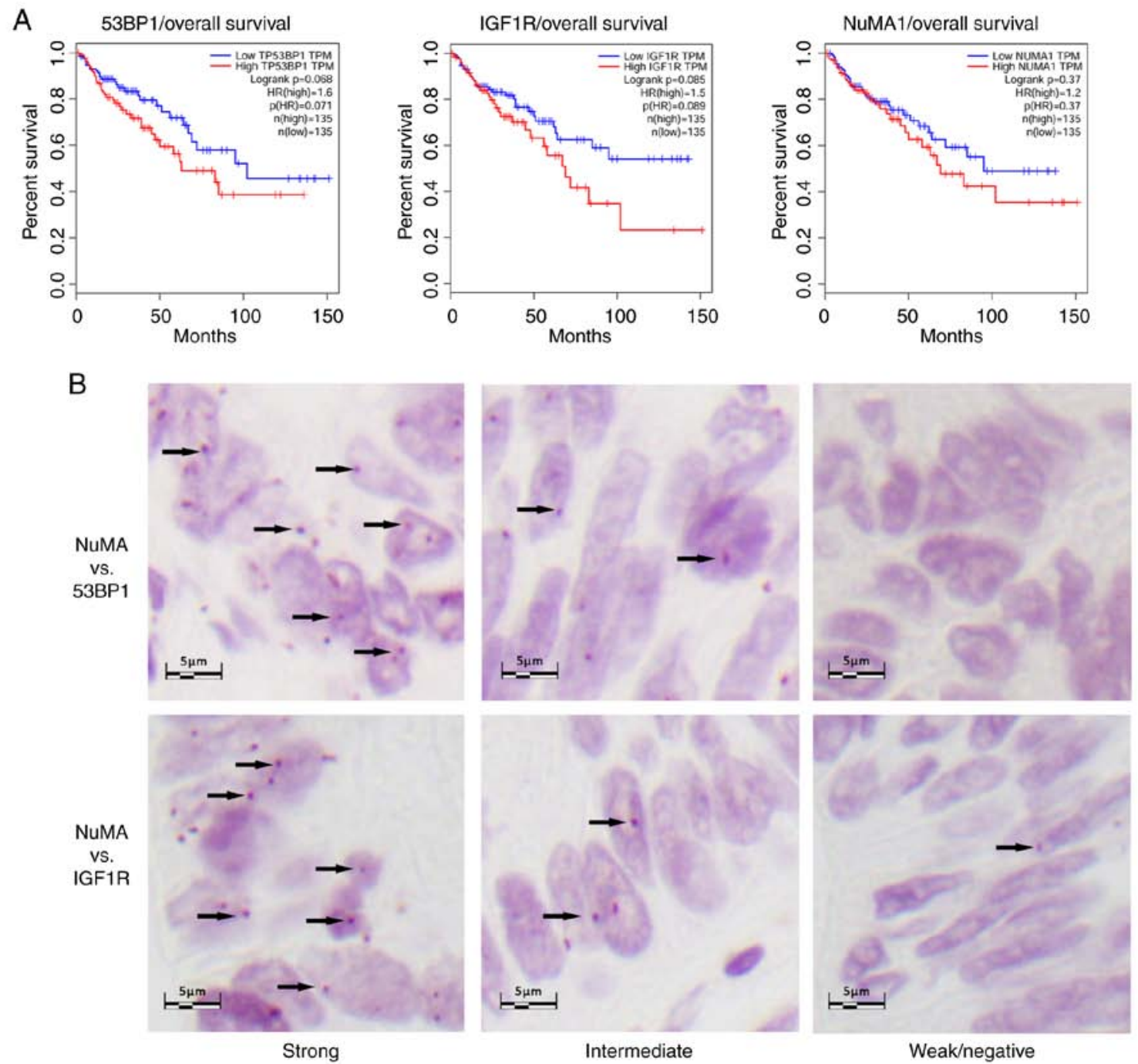

C

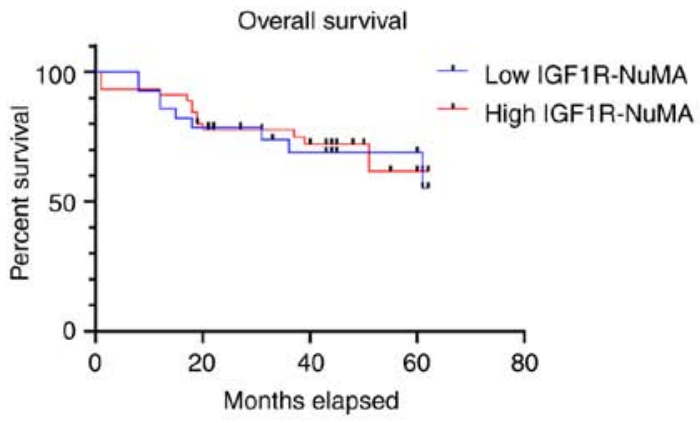

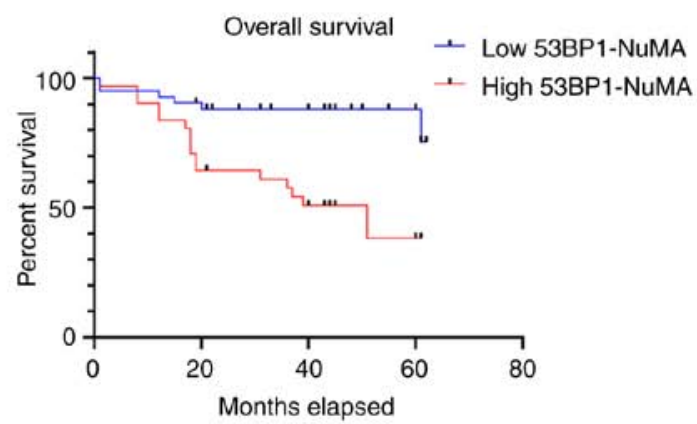

Figure 4. Colocalization of NuMA and 53BP1 in the cell nucleus predicts poor prognosis in patients with colorectal cancer. (A) Survival analysis based on TCGA. No significant association between the expression of IGF1R, 53BP1 or NuMA and overall or disease-free survival in patients with colorectal cancer was identified. (B) Representative microphotographs (magnification, x40) from NuMA-53BP1 and IGF1R-NuMA brightfields in situ PLA. Brown dots mark the colocalizations. (C) Survival analysis for IGF1R-NuMA (left panel) and 53BP1-NuMA (right panel) colocalization in patients with colorectal cancer. Strong nuclear 53BP1-NuMA colocalization was associated with poor survival (P<0.001; low-rank test). NuMA, nuclear mitotic apparatus protein; 53BP1, NuMA-p53-binding protein 1; IGF1R, insulin-like growth factor 1 receptor; TCGA, The Cancer Genome Atlas; PLA, proximity ligation assay.

factor 1, recruiter of U4/U6.U5 tri-snRNP and DEAD-box helicase 5. However, additional studies are required to investigate the potential role of nIGF1R in the function of spliceosomes.

Following proteomic screening, the large nuclear mitotic apparatus protein 1 (NuMA) was identified and validated as an nIGF1R colocalizing partner. NuMA is a coiled-coil nuclear structural protein identified $\sim 40$ years ago, which plays essential roles in mitotic spindle maintenance (45). A previous study reported that an isoform of NuMA could be located in the cytoplasm (46). In the present study, a few cytosolic IGF1R-NuMA colocalization signals and a higher number of cytosolic NuMA1-53BP1 colocalization signals were identified. As the focus was DNA repair, the present analyses were based on nuclear signals only.

Previous studies have indicated that IGF1R facilitates treatment resistance and enhances DSB repair through both 
Table I. Correlation between the PLA staining of IGF1R-NuMA and 53BP1-NuMA colocalization (in the whole cell and in the nucleus) and clinicopathologic characteristics in the 73 cases of human colorectal cancer tissues.

\begin{tabular}{|c|c|c|c|c|c|c|c|c|c|c|c|c|c|}
\hline \multirow[b]{2}{*}{ Parameters } & \multirow[b]{2}{*}{$\mathrm{n}$} & \multicolumn{3}{|c|}{$\begin{array}{l}\text { IGF1R-NuMA in } \\
\text { whole cell }\end{array}$} & \multicolumn{3}{|c|}{$\begin{array}{l}\text { IGF1R-NuMA in } \\
\text { cell nucleus }\end{array}$} & \multicolumn{3}{|c|}{$\begin{array}{l}\text { 53BP1-NuMA } \\
\text { in whole cell }\end{array}$} & \multicolumn{3}{|c|}{$\begin{array}{l}\text { 53BP1-NuMA in } \\
\text { cell nucleus }\end{array}$} \\
\hline & & Low & High & P-value ${ }^{a}$ & Low & High & P-value ${ }^{a}$ & Low & High & P-value ${ }^{a}$ & Low & High & P-value ${ }^{a}$ \\
\hline Total & 73 & 13 & 60 & & 28 & 45 & & 28 & 45 & & 42 & 31 & \\
\hline \multicolumn{14}{|l|}{ Age (years) } \\
\hline$\leq 60$ & 34 & 5 & 29 & 0.518 & 15 & 19 & 0.345 & 15 & 19 & 0.345 & 19 & 15 & 0.790 \\
\hline$>60$ & 39 & 8 & 31 & & 13 & 26 & & 13 & 26 & & 23 & 16 & \\
\hline \multicolumn{14}{|l|}{$\operatorname{Sex}$} \\
\hline Male & 43 & 7 & 36 & 0.683 & 18 & 25 & 0.461 & 18 & 25 & 0.461 & 24 & 19 & 0.722 \\
\hline Female & 30 & 6 & 24 & & 10 & 20 & & 10 & 20 & & 18 & 12 & \\
\hline \multicolumn{14}{|l|}{ Histologic type } \\
\hline Poor and undifferentiated & 16 & 3 & 13 & 0.911 & 6 & 10 & 0.936 & 9 & 7 & 0.096 & 12 & 4 & 0.110 \\
\hline $\begin{array}{l}\text { Well and moderately } \\
\text { differentiated }\end{array}$ & 57 & 10 & 47 & & 22 & 35 & & 19 & 38 & & 30 & 27 & \\
\hline \multicolumn{14}{|l|}{ Depth of tumor invasion } \\
\hline $\mathrm{T} 1, \mathrm{~T} 2$ & 12 & 3 & 9 & 0.039 & 5 & 7 & 0.150 & 5 & 7 & 0.500 & 7 & 5 & 0.288 \\
\hline $\mathrm{T} 3, \mathrm{~T} 4$ & 61 & 5 & 56 & & 18 & 43 & & 21 & 40 & & 31 & 30 & \\
\hline \multicolumn{14}{|l|}{$\begin{array}{l}\text { Regional lymph node } \\
\text { metastasis }\end{array}$} \\
\hline No & 48 & 9 & 39 & 0.771 & 19 & 29 & 0.765 & 20 & 28 & 0.420 & 29 & 19 & 0.490 \\
\hline Yes & 25 & 4 & 21 & & 9 & 16 & & 8 & 17 & & 13 & 12 & \\
\hline \multicolumn{14}{|l|}{ Regional nerve metastasis } \\
\hline No & 70 & 12 & 58 & 0.473 & 26 & 44 & 0.303 & 25 & 45 & 0.025 & 39 & 31 & 0.129 \\
\hline Yes & 3 & 1 & 2 & & 2 & 1 & & 3 & 0 & & 3 & 0 & \\
\hline \multicolumn{14}{|l|}{ Regional vascular metastasis } \\
\hline No & 61 & 9 & 52 & 0.124 & 22 & 39 & 0.364 & 22 & 39 & 0.364 & 34 & 27 & 0.484 \\
\hline Yes & 12 & 4 & 8 & & 6 & 6 & & 6 & 6 & & 8 & 4 & \\
\hline \multicolumn{14}{|c|}{ Cancer relapse (in 12 months) } \\
\hline No & 66 & 12 & 54 & 0.798 & 25 & 41 & 0.797 & 26 & 40 & 0.576 & 40 & 26 & 0.103 \\
\hline Yes & 7 & 1 & 6 & & 3 & 4 & & 2 & 5 & & 2 & 5 & \\
\hline \multicolumn{14}{|l|}{ TNM staging } \\
\hline I, II & 48 & 9 & 39 & 0.771 & 19 & 29 & 0.765 & 20 & 28 & 0.420 & 29 & 19 & 0.490 \\
\hline III, IV & 25 & 4 & 21 & & 9 & 16 & & 8 & 17 & & 13 & 12 & \\
\hline
\end{tabular}

${ }^{a} \chi^{2}$-test, $\mathrm{P}<0.05$ indicates statistical significance. Significant $\mathrm{P}$-values are indicated in bold print. PLA, proximity ligation assay; nIGF1R, nuclear insulin-like growth factor 1 receptor; NuMA, nuclear mitotic apparatus protein 1; 53BP1, p53-binding protein 1.

the HR and NHEJ pathways (24). p53-binding protein 1 (53BP1) is a key determinant in DNA double-strand break (DSB) repair pathway choice and was verified to colocalize with nIGF1R. Based on the current analysis, MDC1, RIF1, DNA-PKcs and Ku80 were identified by IP-MS as nIGF1R interactors. Several key components of DSB repair, such as PARP1, DNA topoisomerase I, DNA topoisomerase II (TOPII) $\alpha$ and TOPII $\beta$ were also identified, suggesting that nIGF1R plays an important role in DSB repair pathways, which prompted the current study to investigate the potential participation of nIGF1R in the regulation of the NuMA-53BP1 complex. The present data confirmed the regulatory role of IGF1R. The nuclear NuMA-53BP1 complex was increased in
$\mathrm{R}^{-}$compared with $\mathrm{R}^{+}$cells [significant changes observed from $30 \mathrm{~min}$ to $2 \mathrm{~h}$ post-ionizing radiation (IR)]. During DSB repair, 53BP1 serves as a molecular scaffold that recruits additional DSB-responsive proteins to damaged chromatin (47). 53BP1 needs to bind to NuMA in a storage-like capacity to be readily available for DNA repair in case of DNA damage (23). Therefore, a decreased in NuMA-53BP1 colocalization was expected in $\mathrm{R}^{+}$cells following IR. However, the possibility that other complementary mechanisms were activated, which recruited more 53BP1 to NuMA to form a dynamic 53BP1 turnover as a response, could not be excluded.

The present results did not provide any information about the location of IGF1R-NuMA interaction and the 
mechanism behind the IGF1R-NuMA-53BP1 interaction. The NuMA-53BP1 interaction was reported to be located in the nucleoplasm when there is no DSB repair (23). The fact that IGF1R-NuMA colocalization was not inducible by IR in the present study suggested that the interaction most likely does not occur at the chromatin surrounding the DSB site, despite the structural and chromosome-binding roles of NuMA (48), as well as the transcription regulatory function of nIGF1R through DNA binding (14). The mechanism behind IGF1R-NuMA-53BP1 interactions could be either that IGF1R-NuMA and NuMA-53BP1 interactions are mutually exclusive or that they form a tripartite complex. Considering the non-dynamic feature of IGF1R-NuMA interaction, the tripartite complex hypothesis is likely; the dynamic turnover of 53BP1, which kept the NuMA-53BP1 colocalization relatively stable in $\mathrm{R}^{+}$cells, was interrupted, resulting in an elevation of nuclear NuMA-53BP1 colocalization in IGF1R-negative $\mathrm{R}^{-}$cells following IR. However, further experimental evidence is required to confirm this hypothesis.

In addition to cellular evidence, a correlation between IGF1R and the NuMA-53BP1 interaction in the present study in a clinical cohort of patients with colorectal cancer would further support the current findings. However, this information could not be obtained due to technical issues. The PLA results indicated that high levels of nuclear NuMA-53BP1 colocalization in the tumor cells were significantly associated with poor overall survival. Patients with a high level of NuMA-53BP1 colocalization were prone to exhibiting a disruption of normal 53BP1-dependent DSB-repair, which could lead to more rapid tumor progression. Although it should be noted that the present cohort only involved patients that had not received chemotherapy or radiotherapy prior to surgical intervention, the significance of NuMA-53BP1 in treatment resistance could not be sufficiently explained. No significant association was identified between IGF1R-NuMA colocalization and patient survival in the current cohort. Based on our hypothesis from the cellular experiment, the IGF1R-NuMA and IGF1R-53BP1 interactions may be consistent with the dynamic change of NuMA-53BP1 colocalization. Future well-designed studies that focus on the dynamic changes and interactive functions of the IGF1R-NuMA-53BP1 complex in post-IR tissue samples are warranted to obtain a deeper understanding of this mechanism.

In conclusion, the interactome of nIGF1R in colorectal cancer was presented herein. nIGF1R interacted with NuMA and appeared to regulate the NuMA-53BP1 interaction. In clinical colorectal cancer tissues, the NuMA-53BP1 interaction was associated with poor overall survival and could therefore serve as a molecular treatment target for those patients. The present study results might shed light on the DNA repair-related function of nIGF1R and benefit the development of novel IGF1R-related cancer treatments.

\section{Acknowledgements}

Not applicable.

\section{Funding}

This study was supported by the Swedish Cancer Foundation, Swedish Research, the Cancer Society in Stockholm,
Swedish Children Cancer Society, Stockholm County Council, Karolinska Institute, China Scholarship Council (grant no. CSC201706370014) and the National Natural Science Foundation of China (grant nos. 81201904 and 81974386).

\section{Availability of data and materials}

The datasets used and/or analyzed during the current study are available from the corresponding author on reasonable request.

\section{Authors' contributions}

YL, ZC, OL and FH conceived the study. CY, YZ, NS and $\mathrm{CH}$ were responsible for data analysis. OL, ZC, FH and $\mathrm{CY}$ were responsible for funding acquisition. CY, YZ, NS, PZ, XT, LM and $\mathrm{ZC}$ were responsible for performing the experiments. PZ, $\mathrm{XT}, \mathrm{LM}$ and $\mathrm{ZC}$ were responsible for obtaining the resources. YL and ZC supervised the study. CY wrote the original draft. YL, OL and FH wrote, reviewed and edited the manuscript. All authors read and approved the final manuscript.

\section{Ethics approval and consent to participate}

The study was conducted according to the guidelines of the Declaration of Helsinki and approved by the Ethics Committee of Xiangya Hospital of Central South University (Changsha, China; approval no. 201403168). Informed consent was obtained from all patients involved in the study.

\section{Patient consent for publication}

Not applicable.

\section{Competing interests}

The authors declare that they have no competing interests.

\section{References}

1. Dekker E, Tanis PJ, Vleugels JLA, Kasi PM and Wallace MB: Colorectal cancer. Lancet 394: 1467-1480, 2019.

2. Mahar AL, Compton C, Halabi S, Hess KR, Weiser MR and Groome PA: Personalizing prognosis in colorectal cancer: A systematic review of the quality and nature of clinical prognostic tools for survival outcomes. J Surg Oncol 116: 969-982, 2017.

3. Fakih MG: Metastatic colorectal cancer: Current state and future directions. J Clin Oncol 33: 1809-1824, 2015.

4. Martini G, Troiani T, Cardone C, Vitiello P, Sforza V, Ciardiello D, Napolitano S, Della Corte CM, Morgillo F, Raucci A, et al: Present and future of metastatic colorectal cancer treatment: A review of new candidate targets. World J Gastroenterol 23: 4675-4688, 2017.

5. Dyer AH, Vahdatpour C, Sanfeliu A and Tropea D: The role of insulin-like growth factor 1 (IGF-1) in brain development, maturation and neuroplasticity. Neuroscience 325: 89-99, 2016.

6. Lin Y, Liu H, Waraky A, Haglund F, Agarwal P, JernbergWiklund $\mathrm{H}$, Warsito D and Larsson O: SUMO-modified insulin-like growth factor 1 receptor (IGF-1R) increases cell cycle progression and cell proliferation. J Cell Physiol 232: 2722-2730, 2017.

7. Heidegger I, Kern J, Ofer P, Klocker H and Massoner P: Oncogenic functions of IGF1R and INSR in prostate cancer include enhanced tumor growth, cell migration and angiogenesis. Oncotarget 5: 2723-2735, 2014.

8. Riedemann J and Macaulay VM: IGF1R signalling and its inhibition. Endocr Relat Cancer 13 (Suppl 1): S33-S43, 2006. 
9. Rodrigues Alves APN, Fernandes JC, Fenerich BA, Coelho-Silva JL, Scheucher PS, Simões BP, Rego EM, Ridley AJ, Machado-Neto JA and Traina F: IGF1R/IRS1 targeting has cytotoxic activity and inhibits PI3K/AKT/mTOR and MAPK signaling in acute lymphoblastic leukemia cells. Cancer Lett 456 : $59-68,2019$.

10. Zorea J, Prasad M, Cohen L, Li N, Schefzik R, Ghosh S, Rotblat B, Brors B and Elkabets M: IGF1R upregulation confers resistance to isoform-specific inhibitors of PI3K in PIK3CA-driven ovarian cancer. Cell Death Dis 9: 944, 2018.

11. Warsito D, Lin Y, Gnirck AC, Sehat B and Larsson O: Nuclearly translocated insulin-like growth factor 1 receptor phosphorylates histone $\mathrm{H} 3$ at tyrosine 41 and induces SNAI2 expression via Brg1 chromatin remodeling protein. Oncotarget 7: 42288-42302, 2016

12. Packham S, Warsito D, Lin Y, Sadi S, Karlsson R, Sehat B and Larsson O: Nuclear translocation of IGF-1R via p150(Glued) and an importin- $\beta /$ RanBP2-dependent pathway in cancer cells. Oncogene 34: 2227-2238, 2015.

13. Warsito D, Sjostrom S, Andersson S, Larsson O and Sehat B: Nuclear IGF1R is a transcriptional co-activator of LEF1/TCF. EMBO Rep 13: 244-250, 2012.

14. Sehat B, Tofigh A, Lin Y, Trocmé E, Liljedahl U, Lagergren J and Larsson O: SUMOylation mediates the nuclear translocation and signaling of the IGF-1 receptor. Sci Signal 3: ra10, 2010.

15. Aleksic T, Verrill C, Bryant RJ, Han C, Worrall AR, Brureau L, Larré S, Higgins GS, Fazal F, Sabbagh A, et al: IGF-1R associates with adverse outcomes after radical radiotherapy for prostate cancer. Br J Cancer 117: 1600-1606, 2017.

16. Wang Y, Yuan JL, Zhang YT, Ma JJ, Xu P, Shi CH, Zhang W, $\mathrm{Li}$ YM, Fu Q, Zhu GF, et al: Inhibition of both EGFR and IGF1R sensitized prostate cancer cells to radiation by synergistic suppression of DNA homologous recombination repair. PLoS One 8: e68784, 2013.

17. Guerard M, Robin T, Perron P, Hatat AS, David-Boudet L, Vanwonterghem L, Busser B, Coll JL, Lantuejoul S, Eymin B, et al: Nuclear translocation of IGF1R by intracellular amphiregulin contributes to the resistance of lung tumour cells to EGFR-TKI. Cancer Lett 420: 146-155, 2018.

18. Her J and Bunting SF: How cells ensure correct repair of DNA double-strand breaks. J Biol Chem 293: 10502-10511, 2018.

19. Wright WD, Shah SS and Heyer WD: Homologous recombination and the repair of DNA double-strand breaks. J Biol Chem 293 10524-10535, 2018.

20. Chang HHY, Pannunzio NR, Adachi N and Lieber MR: Non-homologous DNA end joining and alternative pathways to double-strand break repair. Nat Rev Mol Cell Biol 18: 495-506, 2017.

21. Escribano-Diaz C, Orthwein A, Fradet-Turcotte A, Xing M Young JT, Tkáč J, Cook MA, Rosebrock AP, Munro M, Canny MD, et al: A cell cycle-dependent regulatory circuit composed of 53BP1-RIF1 and BRCA1-CtIP controls DNA repair pathway choice. Mol Cell 49: 872-883, 2013.

22. Chapman JR, Barral P, Vannier JB, Borel V, Steger M, Tomas-Loba A, Sartori AA, Adams IR, Batista FD and Boulton SJ: RIF1 is essential for 53BP1-dependent nonhomologous end joining and suppression of DNA double-strand break resection. Mol Cell 49: 858-871, 2013

23. Salvador Moreno N, Liu J, Haas KM, Parker LL, Chakraborty C, Kron SJ, Hodges K, Miller LD, Langefeld C, Robinson PJ, et al: The nuclear structural protein NuMA is a negative regulator of 53BP1 in DNA double-strand break repair. Nucleic Acids Res 47: 2703-2715, 2019

24. Chitnis MM, Lodhia KA, Aleksic T, Gao S, Protheroe AS and Macaulay VM: IGF-1R inhibition enhances radiosensitivity and delays double-strand break repair by both non-homologous end-joining and homologous recombination. Oncogene 33 5262-5273, 2014

25. Waraky A, Lin Y, Warsito D, Haglund F, Aleem E and Larsson O: Nuclear insulin-like growth factor 1 receptor phosphorylates proliferating cell nuclear antigen and rescues stalled replication forks after DNA damage. J Biol Chem 292: 18227-18239, 2017.

26. Doncheva NT, Morris JH, Gorodkin J and Jensen LJ: Cytoscape StringApp: Network analysis and visualization of proteomics data. J Proteome Res 18: 623-632, 2019.
27. Bindea G, Mlecnik B, Hackl H, Charoentong P, Tosolini M, Kirilovsky A, Fridman WH, Pagès F, Trajanoski $Z$ and Galon J: ClueGO: A Cytoscape plug-in to decipher functionally grouped gene ontology and pathway annotation networks. Bioinformatics 25: 1091-1093, 2009.

28. Huang C, Yuan W, Lai C, Zhong S, Yang C, Wang R, Mao L, Chen Z and Chen Z: EphA2-to-YAP pathway drives gastric cancer growth and therapy resistance. Int J Cancer 146: 1937-1949, 2020.

29. ten Have S, Boulon S, Ahmad Y and Lamond AI: Mass spectrometry-based immuno-precipitation proteomics-the user's guide. Proteomics 11: 1153-1159, 2011.

30. Kakarougkas A and Jeggo PA: DNA DSB repair pathway choice: An orchestrated handover mechanism. Br J Radiol 87: 20130685 , 2014.

31. Xu Y and Her C: Inhibition of topoisomerase (DNA) I (TOP1): DNA damage repair and anticancer therapy. Biomolecules 5: $1652-1670,2015$

32. Rocha JC, Busatto FF, Guecheva TN and Saffi J: Role of nucleotide excision repair proteins in response to DNA damage induced by topoisomerase II inhibitors. Mutat Res Rev Mutat Res 768: 68-77, 2016

33. de Lange T: Shelterin-mediated telomere protection. Ann Rev Genet 52: 223-247, 2018.

34. Maiato H and Pereira AJ: Cell division: NuMA bears the load in the spindle. Curr Biol 27: R765-R767, 2017.

35. Gallini S, Carminati M, De Mattia F, Pirovano L, Martini E, Oldani A, Asteriti IA, Guarguaglini G and Mapelli M: NuMA phosphorylation by Aurora-A orchestrates spindle orientation. Curr Biol 26: 458-469, 2016.

36. Kotak S and Gonczy P: Mechanisms of spindle positioning: Cortical force generators in the limelight. Curr Opin Cell Biol 25: 741-748, 2013.

37. Werner H, Sarfstein R and Bruchim I: Investigational IGF1R inhibitors in early stage clinical trials for cancer therapy. Expert Opin Investig Drugs 28: 1101-1112, 2019.

38. Qu X, Wu Z, Dong W, Zhang T, Wang L, Pang Z, Ma W and Du J: Update of IGF-1 receptor inhibitor (ganitumab, dalotuzumab, cixutumumab, teprotumumab and figitumumab) effects on cancer therapy. Oncotarget 8: 29501-29518, 2017.

39. Yee D: Anti-insulin-like growth factor therapy in breast cancer. J Mol Endocrinol 61: T61-T68, 2018

40. Pollak M: The insulin and insulin-like growth factor receptor family in neoplasia: An update. Nat Rev Cancer 12: 159-169, 2012.

41. Aleksic T, Gray N, Wu X, Rieunier G, Osher E, Mills J, Verrill C, Bryant RJ, Han C, Hutchinson K, et al: Nuclear IGF1R interacts with regulatory regions of chromatin to promote RNA Polymerase II recruitment and gene expression associated with advanced tumor stage. Cancer Res 78: 3497-3509, 2018.

42. Solomon-Zemler R, Pozniak Y, Geiger T and Werner H: Identification of nucleolar protein NOM1 as a novel nuclear IGF1R-interacting protein. Mol Genet Metab 126: 259-265, 2019.

43. Solomon-Zemler R, Sarfstein R and Werner H: Nuclear insulin-like growth factor-1 receptor (IGF1R) displays proliferative and regulatory activities in non-malignant cells. PLoS One 12: e0185164, 2017

44. Wickramasinghe VO and Venkitaraman AR: RNA processing and genome stability: Cause and consequence. Mol Cell 61: 496-505, 2016

45. Radulescu AE and Cleveland DW: NuMA after 30 years: The matrix revisited. Trends Cell Biol 20: 214-222, 2010.

46. Wu J, Xu Z, He D and Lu G: Identification and characterization of novel NuMA isoforms. Biochem Biophys Res Commun 454: 387-392, 2014

47. Panier S and Boulton SJ: Double-strand break repair: 53BP1 comes into focus. Nat Rev Mol Cell Biol 15: 7-18, 2014.

48. Serra-Marques A, Houtekamer R, Hintzen D, Canty JT, Yildiz A and Dumont S: The mitotic protein NuMA plays a spindle-independent role in nuclear formation and mechanics. J Cell Biol 219: e202004202, 2020.

This work is licensed under a Creative Commons Attribution-NonCommercial-NoDerivatives 4.0 International (CC BY-NC-ND 4.0) License. 